\title{
Communicating and collaborating across nations, professions and disciplines in restorative justice
}

\author{
Ian D. Marder
}

To cite this article: lan D. Marder (2016) Communicating and collaborating across nations, professions and disciplines in restorative justice, Restorative Justice, 4:2, 237-246, DOI: 10.1080/20504721.2016.1197529

To link to this article: https://doi.org/10.1080/20504721.2016.1197529

曲 Published online: 29 Jul 2016.

Submit your article to this journal

Џlll Article views: 176

View Crossmark data \lceil 


\section{Communicating and collaborating across nations, professions and disciplines in restorative justice}

Ian D. Marder

PhD Student, Centre for Criminal Justice Studies and Centre for Law and Social Justice, School of Law, University of Leeds, Leeds, UK

\section{Introduction}

The use of restorative justice in education, criminal justice and other contexts has proliferated in a number of jurisdictions in recent years, if we take a dialogic definition of the term (Hoyle, 2010). At the same time, it has been possible to observe growing levels of communication and collaboration across borders, as well as between disciplines and professions, within the broader restorative field. While the benefits of these partnerships and relationships may be difficult to quantify, few would deny that they should be nurtured, if the ultimate aim is to maximise the benefits and minimise the risks of the use of restorative approaches to crime, harm and conflict.

This text argues that communication and collaboration between those involved in restorative justice (RJ) in different settings and capacities should be further enhanced and structured. It outlines the activities of a new organisation, the Community of Restorative Researchers, simultaneously exploring the changing nature of communication and collaboration in the Internet age, and analysing the prospects, benefits and limitations of this and other attempts by restorativists to connect with one another. The Note finishes by briefly considering what it means, or should mean, to be a restorative researcher.

\section{Enhancing and organising communication and collaboration between researchers and others involved in restorative justice in different capacities}

There are many well-known differences of opinion within the restorative field, with those regarding its name being perhaps both the most fundamental and hotly contested. Inextricably linked to the question of nomenclature is that of the meaning and scope of the selected terminology; in essence, what do we mean when we say something is or is not restorative? Similarly, there is 
debate between and within research, activism, practice and policymaking regarding the priorities and end goals of the restorative movement, as well as over the extent to which this work should take place within the boundaries of existing systems and processes.

There have been no shortages of efforts, however, to bring restorative reformers together to encourage agreement upon a common purpose. Many associations, both national and supranational, aim to enable academics, practitioners, policymakers and civil society to organise with a view to 'making RJ happen' (Wright, 2015). Some of these operate mostly within a single jurisdiction, such as RJ forums in Scotland, Sweden and Israel, as well as the National Association of Community and Restorative Justice (NACRJ) in the United States and the Restorative Justice Council (RJC) in England and Wales. International organisations include the European Forum for Restorative Justice (EFRJ), the Asia Pacific Forum for Restorative Justice (APFRJ), Prison Fellowship International, the International Institute for Restorative Practices (IIRP), the IARS International Institute, and Restorative Justice International (RJI). Many of these organisations have had notable successes in advancing the use of RJ, or in ensuring its safety and effectiveness where it already takes place.

In addition, there are a number of international agreements which have brought us closer to a collective understanding of the role and purpose of RJ. For example, the Declaration of Leuven, an influential document dating from the late 1990s, was written by delegates at a meeting of the nowdefunct International Network for Research on Restorative Justice for Juveniles (Walgrave, 1997). Subsequently, work by Terre des Hommes $(2009,2015)$ culminated in both the Lima Declaration on Restorative Juvenile Justice and the Ibero-American Declaration on Restorative Juvenile Justice. Each of these documents, alongside agreements pertaining to the principles of RJ by the Council of Europe and the United Nations, stress the need to develop this work further and to ensure that it is inclusive of researchers, while demonstrating the potential of collaboration.

Indeed, anybody who supports the expansion of RJ should be encouraged by the level of openess and collegiality observable within the field. This allows information to flow freely between professions, disciplines and jurisdictions. Moreover, it is indicative of a willingness to both learn about and reflect on the range of perspectives held by those working in RJ in different contexts and capacities. These conditions are optimal for collaborative research, and it is incumbent on academics to be proactive in making the requisite connections, networks and relationships in order to gain access to data and participants, disseminate and triangulate research findings, and influence policy and practice.

One way to achieve this is to create and sustain an enabling infrastructure. In his book Firing back, Bourdieu makes the case for the use of organisations 
to facilitate researcher involvement in social movements. He states: 'We must work to design new forms of organisation capable of bringing together researchers and activists in a collective work of critique and proposition, leading to novel forms of mobilisation and action' (2003: 14, emphasis in original). In RJ, it could be said that the 'activists' include former participants in RJ, penal and educational reformers and members of civil society, as well as supportive practitioners and policymakers working in justice agencies or government departments, often referred to as 'moral entrepreneurs' (Clairmont, 2011). The purpose of creating such organisations, Bourdieu contends, would be 'to collectively discuss and elaborate a set of analyses and proposals for progress that today exist only in the virtual state of private and isolated thoughts or circulate in fringe publications, confidential reports or esoteric journals' (2003: 15-16). The structuring of collaboration in this way would enable a group of researchers and activists to inject new concepts into the mainstream consciousness.

Dissenters to Bourdieu's position might deny the role of researchers in actively driving social change, imploring that they instead remain neutral or objective. Yet, this assumes that value-neutral social science is both achievable and desirable (Weber, 1949 [1904]). I am not aware of any methodological approach that allows social scientists to divorce their research entirely from normative considerations, or to control for all of the possible variables to the point where they can refer to their work as objective or scientific in the true sense of those terms (Popper, 2002 [1963]). Whether researchers are conscious of it or not, their work is imbued with their individual preferences as to how the social world should develop. Of course, reflexivity is vital, allowing researchers to be mindful and transparent in their decision making, and to account for how their attitudes and choices influence their epistemologies, methodologies and analyses. Still, it is one thing to state that researchers must retain their independence and their use of rigorous methodologies, and quite another to imply that they should not take an explicit position on the consequences of, and values espoused by, a given society's response to harm and conflict.

In fact, as Aertsen, Vanfraechem, Parmentier, Walgrave and Zinsstag (2013) remark, some of the most significant modern developments in RJ are the direct result of collaboration between researchers, practitioners and policymakers. Citing the case of Belgium, Aertsen et al. note that researchers and practitioners collectively acquired funding, lobbied policymakers and senior practitioners, developed referral pathways, implemented pilot projects and conducted action research for the purpose of evaluating and further developing RJ policy and practice (for more information about Belgium, see Van Dijk, 2004). The implication is that researchers can play a key role in the development of RJ, while both retaining their independence and critical 
voice, and defending restorative principles from cooption by punitive, managerial or actuarial rationales.

\section{Contextualising the foundation of the Community of Restorative Researchers}

During the 2013/14 academic year, my first as a PhD student, I had the opportunity to meet or communicate remotely with a significant number of other $\mathrm{PhD}$ students conducting research on RJ. In my home jurisdiction of England and Wales (and, seemingly, in many others), the ranks of postgraduate researchers in this field appeared to have swollen in recent years, in correlation with the growing number of local experiments into different approaches to the coordination and delivery of RJ. Yet, most of the students to whom I had spoken had made only limited contact with those engaged in similar research in other institutions and with the international restorative community. This was a problem I envisaged being able to rectify by creating an informal network on social media to connect $\mathrm{PhD}$ students who were studying RJ in England and Wales.

As soon as the network was advertised online and in relevant newsletters, I started to receive inquiries and requests to participate from a much broader range of actors. Significantly, most of those who were in contact at this early stage stated that they were not already involved with the existing international networks. This seemed to be particularly true for activists and moral entrepreneurs from countries not covered by the aforementioned continental forums, recently hired project managers, volunteer facilitators and earlycareer researchers. For this reason, the decision was made to remove any professional or geographical restriction on participation in the network, and to develop it in such a way that it could cater to each of these groups.

Today, the Community of Restorative Researchers (CoRR) is an international, interdisciplinary and inter-profession research network. It acts primarily as a hub through which people can share or request information and make connections with other persons or organisations. CoRR's largest discussion group, found on Facebook, comprises around 600 participants. These include students and researchers at all stages of their education and careers, as well as volunteer, generalist and specialist restorative practitioners, project managers, policymakers, activists and former RJ participants. We also have a Facebook page, on which research, news and events are shared, as well as a Twitter page (@restorative_res) and further discussion groups on LinkedIn and the Restorative Forum. Three project developers assist with various aspects of the network's activities in a voluntary capacity, and we have a 22-person International Advisory Board, comprised of persons with a wealth and breadth of experience in RJ, and from a variety of nations, disciplines and professional backgrounds. 


\section{Situating the infrastructure and activities of CoRR in the international restorative community}

Were CoRR to operate according to its original, narrow scope, there would be limited risk of its activities overlapping with those of existing organisations. After almost two years of expanding in size and encouraging its participants to engage with the international restorative community, however, the overwhelming majority of CoRR's participants are now connected to one or more of these other groups. This means that care must be taken not to duplicate or compete with their work, lest the influence, synergy and reciprocity of the restorative community be weakened.

The first way of avoiding this is through CoRR's structure. Unlike many of the organisations mentioned earlier, CoRR has no formal membership. The absence of membership fees ensures that we are not competing with others for that particular resource. Rather, CoRR's participants are either selfdefined or characterised by their connection to one or more of the social media groups we operate.

Of course, this structure has its limitations. First, we have no regular sources of funding. This means that we are not able to employ anyone to assist with the network, nor can we pay to promote ourselves. Second, this arrangement could result in participants taking less ownership over the organisation than paying members perhaps would have. While the absence of cash reserves can frustrate, a lack of participant ownership does not seem to have materialised. Volunteers for the advisory board were forthcoming, and participants provide information and assistance to each other as often as it is requested.

The second way CoRR aims to minimise overlap with other organisations is to focus on new media approaches to content creation and dissemination. CoRR does not have its own website, but one is not essential as long as others are willing to host our content and facilitate communication between our participants. Consequently, our relationship with those who publish our content, such as Restorative Works, the Restorative Forum, the EFRJ and TransConflict, is mutually beneficial. It increases our content's legitimacy and readership, while the editorial processes of these websites improve its quality and allow us to build collegiate relationships with the organisations which run them. Moreover, as we share articles published on these websites, we raise awareness of their work and encourage our participants to visit them. This facilitates coexistence, copromotion and the linking of previously unconnected persons to the wider RJ community, all without competition or duplication.

Moreover, the primary purpose of CoRR is not to produce original research. Rather, it chiefly acts as a hub, through which research, news stories, media representations of RJ, commentary, conference information, 
employment and funding opportunities and other relevant materials can be disseminated.

The proportion of high-quality, empirical work in our field which is not used to its maximum potential is too high. It is essential that researchers be more proactive in presenting their work to practitioners and policymakers in an accessible format, and in encouraging and assisting them to implement the findings. The few materials CoRR does produce, therefore, are designed primarily with the aim of making existing knowledge more accessible. One example is our podcast series, Restorative Conversations (hosted by SoundCloud, and available on iTunes and TuneIn), for which we interview prominent persons and innovators in RJ research and practice about their recent work. We also produced an edited collection of short summaries of research, activism, policymaking and practice under the title Restorative introductions (Marder, 2015). This work aims to complement the efforts of, among others, the Peace Alliance which produces the podcast series Restorative justice on the rise, and the Restorative Forum which has developed a series of YouTube video interviews, entitled Restorative perspectives. All of this work is underpinned by the assumption that it is as important to ensure that existing research and knowledge is fully understood and utilised as it is to produce new material.

The use of electronic communications means that almost all online materials are equally easy to share, and that anyone with Internet access is able to be involved in a debate at any time. These are perhaps two of its most attractive features, while simultaneously presenting its most significant challenges. On the one hand, direct (and, with social media, public) communication tools allow us to maximise opportunities for people to participate in dialogue, thereby increasing the quantity and diversity of participating voices. For example, individuals without the resources to travel can now contribute to the drafting of collaborative documents, as demonstrated by RJI's recent working groups. On the other hand, the sheer volume of information we are exposed to requires us to have both the capacity to absorb it all, and the ability and inclination to discriminate between that which is reliable and that which is not. The latter can be particularly difficult given the varying quality of online content. Social media, and the Internet generally, allows for the propagation of assumptions which have not been empirically verified or peerreviewed.

Moreover, the ease with which social media groups and pages can be accessed and commented on makes active moderation both extremely important and highly complicated. In a field which both advocates radical social change and values honesty and inclusiveness, it is essential to promote an open and critical dialogue. This is the only way to ensure that the conjecture of those who are wedded to one or another ideological position is disputed. At the same time, moderators must determine what level of aggression they are 
willing to tolerate, as well as the extent to which they will allow their platforms to be appropriated by one or more participants for personal gain. Whether a given communication falls on one side of these fine lines or the other is often difficult to judge. Thus, these decisions can present daily problems to moderators who are required to balance the needs and interests of all of their participants.

The third way in which CoRR operates is by helping our participants to make new connections. So far, this has involved four approaches:

- connecting practitioners, project managers and policymakers in different geographical areas, allowing them to share experiences and learn from previous or ongoing attempts to implement similar projects;

- encouraging relationship building between researchers and $\mathrm{PhD}$ students on the one hand, and those involved in project implementation on the other. This increases the likelihood of researchers gaining entry to these organisations for the purpose of study, and enhances the access of practitioners, project managers and policymakers to researchers and their findings;

- fostering conversations between English-speaking and non-English-speaking jurisdictions, ensuring that as many people consider and engage with as wide a variety of perspectives and approaches as possible;

- and connecting students and young people to practice, allowing them to build networks of their own, and to learn about how organisations and policymaking processes operate.

Social media facilitates each of these. The 'tag' function, for example, allows participants to draw the attention of others to a post and its poster. This has enabled many of CoRR's participants to be introduced to others engaged in similar lines of inquiry, or to those who are able to assist them in some way. It has also been used to solicit information on a particular topic, alert people to job opportunities and plan joint submissions to conferences. Again, this approach is conducive to collaboration and communication, while avoiding competition and duplication,

\section{Restorative research or restorative researching?}

Should the last two words in 'Community of Restorative Researchers' be interpreted as 'those who research RJ', or as 'those who conduct research restoratively'? This article has outlined the instrumental benefits of communication and collaboration, but in the study of RJ, this can conceivably be justified on purely normative grounds. Perhaps any individual or group which declares a preference for 'restorativeness' ought to reflect this in their working practices, or at least consider what this might look like. 
Using a circle process to negotiate access, to conduct interviews or focus groups, or to give feedback on findings is one method of using a restorative practice in research. But what of the integration of restorative principles more broadly into this work? Perhaps this might involve conducting research with the aim of satisfying the needs and interests of stakeholders, or taking steps to maximise the inclusivity of the research process. Already, though, it is possible to see how such principles could come into conflict with other requirements and pressures faced by researchers, not least relating to the time, financial and human resources at our disposal. In aspiring to research restoratively, researchers would acquire many new obligations which may not always be achievable in practice.

Indeed, what a frightening thought: having to practice what we preach! Social researchers are already faced with considerable difficulties in integrating the normative and the practical (Karstedt, 2011), and often there is little that academics feel that they can do to circumvent the restrictions placed upon them. As with the implementation of methodological principles, adherence to restorative principles would vary, depending on the individual researchers' ability and inclination to navigate practical enablers and barriers on a day-to-day basis. Consider how often a methodologically principled approach to data collection can mutate into a pragmatic, hybrid approach. Researchers are often left (or, at least, we perceive ourselves to be left) with little choice but to do what is feasible, and to justify our approach retrospectively. Even with the purest of intent, the extent to which an individual researcher implements restorative principles into their work will vary over time and space.

Further thought is required to define what it would mean to be restorative in research, to establish what this would look like in practice, and to determine the minimum standards for being 'restorative enough' to satisfy the label. Yet, if we can only conclude upon examination that total fidelity to restorative principles is likely beyond the grasp of researchers, then this might bring us closer to an understanding of the gap between theory and practice apparent in RJ implementation more broadly (Daly, 2003). If this exercise encourages researchers to reconsider the standards to which they hold those involved in RJ implementation and delivery-and, perhaps, to temper their judgements of practitioner and policymaker 'failure' to adhere fully to restorative principles -then maybe that alone would make it a worthwhile (and restorative) endeavour.

\section{Future prospects for CoRR and for the international restorative community}

Research into restorative processes, policies and principles usually aims to assist in maximising the benefits and minimising the risks of the growing 
use of RJ. As a research network, CoRR intends to contribute to this goal by promoting an open and critical dialogue within the field. It does this primarily by acting as a hub for the enhancing and organising of communication and collaboration, through which its participants can connect, share information and find ways to increase the accessibility and usage of the abundance of existing knowledge.

Many uncertainties remain regarding how the international RJ community will develop. As our discipline is gradually recognised as a discrete social science (Wachtel, 2013), however, further integration of localised, intradiscipline or intra-profession RJ groups seems both inevitable and desirable. What is clear is that no single organisation has the resources to provide all of the researching, dissemination and networking services required to bring RJ into the mainstream on a global level. Let us work collectively to ensure that, between us, we do this as comprehensively as possible.

\section{Acknowledgements}

I would like to thank Anne Brunelle, Estelle Zinsstag and Ivo Aertsen for their patience and support, and for their help in improving this contribution.

\section{References}

Aertsen, I., Vanfraechem, I., Parmentier, S., Walgrave, L. \& Zinsstag, E. (2013). It takes two to tango: practitioners and researchers on the floor of restorative justice. Restorative Justice: An International Journal, 1(3), 305-310.

Bourdieu, P. (2003). Firing back: against the tyranny of the market 2. London: The New Press.

Clairmont, D. (2011). Penetrating the walls: implementing a system-wide restorative justice approach in the justice system. In E. Elliot \& R. Gordon (eds.), New directions in restorative justice: issues, practice, evaluation (pp. 245-265). London: Routledge.

Daly, K. (2003). Mind the gap: restorative justice in theory and practice. In A. Von Hirsch, J. Roberts, A. Bottoms, K. Roach \& M. Schiff (eds.), Restorative justice and criminal justice: competing or reconcilable paradigms? (pp. 219-236). Oxford: Hart Publishing.

Hoyle, C. (2010). The case for restorative justice. In C. Hoyle \& C. Cuneen (eds.), Debating restorative justice (pp. 1-100). Oxford: Hart Publishing.

Karstedt, S. (2011). Our sense of justice: values, justice and punishment. In S. Parmentier, L. Walgrave, I. Aertsen, J. Maesschalck \& L. Paoli (eds.), The sparking discipline of criminology (pp. 33-58). Leuven: Leuven University Press.

Marder, I. (ed.). (2015). Restorative introductions, http://www.euforumrj.org/wpcontent/uploads/2015/11/Restorative-Introductions-final-pdf.pdf (accessed 17 March 2016).

Popper, K. (2002 [1963]). Conjectures and refutations: the growth of scientific knowledge. London: Routledge.

Terre des Hommes. (2009). Lima declaration on restorative juvenile justice. Lima: Terre des Hommes. 
Terre des Hommes. (2015). Adoption of the Ibero-American declaration of restorative juvenile justice, http://www.tdh.ch/en/news/ibero-american-declaration-juvenilejustice (accessed 16 March 2016).

Van Dijk, C. (2004). Juvenile delinquency and juvenile justice in Belgium, https:// johnjayrec.files.wordpress.com/2012/09/belgium_june_2004.pdf (accessed 16 December 2015).

Wachtel, T. (2013). Dreaming of a new reality: how restorative practices reduce crime and violence, improve relationships and strengthen civil society. Bethlehem: The Piper's Press.

Walgrave, L. (1997). Declaration of Leuven. European Journal on Criminal Policy and Research, 5(4), 118-122.

Weber, M. (1949 [1904]). Objectivity in social science and social policy. In E. Shils \& H. Finch (eds.), The methodology of social sciences (pp. 49-112). Glencoe: Free Press.

Wright, M. (2015). Making it happen or letting it happen. Restorative Justice: An International Journal, 3(1), 119-128. 